\title{
Editorial
}

\section{ULLRICH KOCKEL}

With this issue, $A J E C$ returns to its original format as a journal with, for the time being, two issues per year. When the first issue was published in 1990 by the European Centre for Traditional and Regional Cultures (ECTARC), Europe was a different place. As the director of ECTARC, Franz-Josef Stummann (1990: 7), explained in his introduction to that issue, the 'magical date of 1992', heralding the Single European Market as a significant step towards European integration, had 'a substantial bearing' on the foundation of the journal. Moreover, the Berlin Wall, symbol of the political divide that cut right through Cold War Europe, had crumbled the previous year. German unification was imminent, but very little else seemed predictable. Eighteen years and two Gulf Wars later, not only has the European Union acquired fifteen new member states, ten of them former Communist countries, but we have also been told to perceive a new divide - between a 'new' Europe and an 'old' one.

Simplistically coined in the context of the second Gulf War, this distinction is also reflected in the discourses that have emerged since the late 1980s, pitching a commodity view of the world - as in the concept of 'cultural industries', or the almost universal marriage of cultural studies and business training under the label 'European Studies' - against a critical, more differentiated view that, for much of the past two decades, seems to have been on the retreat. In these circumstances, Stummann's (1990: 9) remark that concepts of 'culture and cultural dynamics need the interdisciplinary orientated anthropologist who maintains the ability to distinguish and to differentiate' is as valid today as it was then; I will come back to the issue of interdisciplinarity.

In the first research article in $A J E C$, founding editor Ina-Maria Greverus (1990: 14) developed a critical perspective on what she described as 'a growing postmodern indifference to the utopian Not-Yet' postulated by the philosopher Ernst Bloch. Discussing an interdisciplinary conference organised by the Westdeutsche Rektorenkonferenz [West German consortium of presidents of universities and colleges] in 1988, she noted (1990: 15) a 
rather 'schizophrenic break' in 'the conviction manifest at the conference that the apparent ease with which we "already" move across boundaries within and between university disciplines offered a substitute for that "NotYet" by which one might begin the serious work of overcoming boundaries in the reality beyond the ghetto of those disciplines.' Greverus diagnosed a 'lack of concern for real conditions and practices as they exist in ... societies and their subordinate institutions such as universities'. Looking around the disciplinary ghettoes that continue to frame the context for much of university research in the early twenty-first century, one can still observe 'the almost manic way in which theoretical pluralism and a variety of methodologies [are] conjured up, supposedly in order to overcome the boundaries between academic disciplines' (1990: 14) while universities seem to be run, then as now, 'by bureaucrats in alliance with conformists and ... "shallow practicists"' (1990: 16). Against this spectre, Greverus issued a rallying call for 'the rare few who are actively seeking out the possibilities of a humanities of the Not-Yet ... to take a critical stance ... not so much by means of cultural pessimism but by expanding our horizons of knowledge' (1990: 16). A key element of this process is the development of a 'reciprocal understanding of Self and other' that cannot be achieved by thinking alone, but requires 'the practice of empirical research as the perceptual experience of otherness'. This 'manifesto for empirical ethnoanthropology' (1990: 17) remains a cornerstone of AJEC.

A second cornerstone is the commitment to the interdisciplinary expanding of our horizons of knowledge. Greverus (1990: 19) argued that anthropology as 'an empirical science ... has to be understood not as a discipline within the current organization of scholarship, but as an interest in knowledge [Erkenntnisinteresse] which extends beyond all particular disciplines'. Many who enjoy the comfort and conceptual safety of canonical disciplinary boxes would suspect such bold claims to be driven by the imperialistic desire of a self-styled 'umbrella discipline'. After playing the fashionable game of multi-disciplinary collaboration, they prefer to return to their silos with the respective canon intact. But their fears are born out of a misreading of the anthropological project, which is not about establishing a meta-discipline to dominate the humanities and beyond, but rather about the legitimacy of diverse modes of inquiry. It is not in any hierarchical 'above', but in that epistemological 'beyond all particular disciplines' that the Not-Yet may be found. 
Greverus outlined the horizons of such knowledge in some detail. Two of these in particular I want to recall here.

The praxis-oriented horizon 'implies encouraging and assisting ... practical action toward the goal of transforming societal structures' (Greverus 1990: 25). This challenge of an applied anthropology goes beyond and sometimes against approaches to intercultural communication in the service of business or military interests, and while the status of 'applied anthropology' remains contested, these issues are today debated widely. Closely connected with the praxis-oriented horizon is the holistic-ecological one. Critical of an 'anthropocentric ecology ... dominated by economic rationality and ... quantitative, measurable differences', Greverus (1990: 26) postulated a human ecology that approaches 'ecological praxis not only via the horizon of material action but also via the horizon of understanding "intended meanings." To develop this perspective further will be a theme for AJEC in 2009.

Along with empirical grounding and praxis-oriented, holistic-ecological interdisciplinarity, a third cornerstone of $A J E C$ is experimental writing, 'a renewed appreciation for the literary aspects of ethnographic textualization, for rhetoric, fiction, and subjectivity', based on 'an awareness of the historical contingency of different modes of writing' (Greverus 1990: 28). This appreciation arises not least from the 'Writing Culture' debate and the development of critical forms of 'native' anthropology that transcend dangerous Euro-(or any other)centrisms; both are crucial aspects of the attempts at 'liberating the ethnological imagination', expressed in the theme of the 2008 Congress of the $S_{0}$ ciété Internationale d'Ethnologie et de Folklore. If AJEC was established as 'a platform for anthropological research on and interpretations of both the potential of living European cultures and the restrictions to their actual and potential life' (Greverus 1990: 29), it has to confront contemporary ideologies that cast any reference to 'Europe', to 'European culture', and certainly to any plurality of 'cultures', as 'essentialising' and therefore a bad thing. The deconstruction of 'essentialisms' has been vitally important for our coming to terms with the unsavoury pasts of our nations and disciplines, and there is no scope for complacency here. However, much of the contemporary debate over 'essentialism' amounts to a silencing of the European voices, regardless of whether these are 'of' Europe, 'in' Europe, or coming from some other corner 
of the globe. This matter cannot be resolved here, but it needs to be engaged with continuously, questioning the Erkenntnisinteresse that informs such debate.

$A J E C$ will continue to have a thematic focus for each issue. For its relaunch as a journal, we invited recent inaugural lectures as a good gauge of where the field of European ethnology and Europeanist anthropology is 'at' right now, and received an interesting range of texts. Three of these deal with cultural heritages, and inevitably address, in one way or another, the issue of essentialism highlighted above. Augmented by a keynote lecture given at a recent Arts and Humanities Research Council conference, they form the thematic focus of this issue, 'Ethnological Approaches to Cultural Heritages'. Other inaugurals will feature in future issues. Invited contributions, like submitted essays, are subject to anonymous peer review by at least one member of the editorial board and one or more outside referees. In addition to articles, AJEC will now carry book reviews and short reports on particularly interesting research in progress. Although our concern is with developing anthropological perspectives on European cultures, we welcome, in the spirit of this Editorial, contributions that go beyond particular disciplines, experiment with different ethnographic genres, or otherwise expand the horizons of anthropological knowledge towards a practically and ecologically inspired 'humanities of the NotYet'.

\section{References}

Greverus, I. (1990), Anthropological Horizons, the Humanities and Human Practice, Anthropological Journal on European Cultures 1 no. 1: 13-33.

Stummann, F. (1990), Europe: Projecting Different Views, Anthropological Journal on European Cultures 1 no. 1: 7-11. 